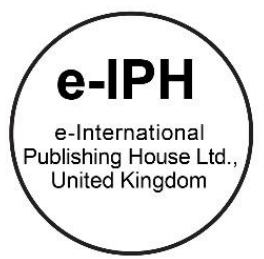

\title{
The Health Benefits of Children by Different Natural Landscape Contacting Level
}

\author{
Tzuhui Angie Tseng ${ }^{1{ }^{*}}$, Ching-Cheng Shen ${ }^{2}$ \\ ${ }^{1}$ Department of Environmental and Cultural Resources. National Hsinchu University of Education, \\ 30014 No. 521 Nanda Rd,. Hsinchu City, Taiwan \\ 2 The Graduate School of Travel Management. National Kaohsiung University of Hospitality and Tourism, \\ 81271 No.1, Songhe Rd., , Kaohsiung City, Taiwan.
}

\begin{abstract}
Previous studies seldom explore the health benefits of different levels of nature exposure on children. 241 valid samples from five primary schools in Hsinchu, Taiwan were investigated. Results showed that comparing to being on school campuses, children would have higher levels of physical activity when visiting neighborhood parks and forest. Only the forest level natural landscape experiences have significant positive impact on enjoying nature, preferences and empathy and sense of belonging. Forest level natural landscape experiences would also positively affect mental health, and physical health is built up through physical activity. Therefore, rural natural settings would be more beneficial to children.
\end{abstract}

(C) 2016. The Authors. Published for AMER ABRA by e-International Publishing House, Ltd., UK. This is an open access article under the CC BY-NC-ND license (http://creativecommons.org/licenses/by-nc-nd/4.0/).

Peer-review under responsibility of AMER (Association of Malaysian Environment-Behaviour Researchers), ABRA (Association of Behavioural Researchers on Asians) and CE-Bs (Centre for Environment-Behaviour Studies), Faculty of Architecture, Planning \& Surveying, Universiti Teknologi MARA, Malaysia.

Keywords: Natural experience, The Connection to Nature Index (CNI) for children; Children's Physical Activity Scale (PAQ-C); Pediatric quality of life questionnaire (PedsQL ${ }^{\mathrm{TM}}$ )

\section{Introduction}

According to Gibson's theory of planned behavior (Gibson, 1979), children are conscious to the function of the environment and landscape elements, and would create different activities in different environments. In recent

\footnotetext{
* Corresponding author. Tel.: +886-930625770

E-mail address: thtseng@mail.nhcue.edu.tw
}

2398-4287 (c) 2016. The Authors. Published for AMER ABRA by e-International Publishing House, Ltd., UK. This is an open access article under the CC BY-NC-ND license (http://creativecommons.org/licenses/by-nc-nd/4.0/).

Peer-review under responsibility of AMER (Association of Malaysian Environment-Behaviour Researchers), ABRA (Association of Behavioural Researchers on Asians) and CE-Bs (Centre for Environment-Behaviour Studies), Faculty of Architecture, Planning \& Surveying, Universiti Teknologi MARA, Malaysia.

DOI: http://dx.doi.org/10.21834/e-bpj.v1i3.362 
years, many environmental psychology/behavioral scholars believe exposing to nature is beneficial to children, and lack of natural experience would obstruct children's development. Louv (2005) presented the term "nature-deficit disorder" for the alienation of the children with nature, and the book also described some symptoms caused by children's lack of nature connection. Davis, Rea and Waite (2006) proposed spending time in the outdoors will help children to develop positive natural value, Wells (2000) stated children whose homes improved the most in terms of greenness after relocating have the highest levels of cognitive functioning following the move. Wells and Evans (2003) noted that natural environment can improve children's psychological well-being. Many evidences have showed the positive effects caused by being in nature, and suggested children who spend time outdoors are more active (Dyment \& Bell, 2008; Bell, Wilson, \& Liu, 2008; Potwarka, Kaczynski, \& Flack, 2008).

Many studies have also recently begun to explore the relationship between children and the natural environment (Bartleet, 1997; Coley, Kuo, \& Sullivan, 1997; Kahn \& Kellert, 2002; Moore, 1986; Sebba, 1991; Sobel, 1993). However, most studies only discussed whether children have been in contact with the natural environment or evaluate the extent of neighborhood greenery, and are in lack of investigating children's exposure to different kinds of the natural landscape environment, as well as various types of natural environmental analysis. Gibson (1979) proposed the environment affordance from the ecological psychology point of view, which is an important factor to predict behavior. The affordance of landscape environment is the possibilities for action provided to children by the type of space. There are various types and level scales of natural landscape environment, yet past researches did not explore the effect of different landscape environment levels on users, which is a deficiency in the definition and categorize of natural landscape environment.

Studies showed the majority of children's preference for natural environment (Korpela, Kyttä, \& Hartig, 2002; Sebba, 1991). Researches regarding benefits from natural landscape on children focused on children's contact with nature to improve their function or well-being (Faber Taylor, and Kuo, \& Sullivan, 2001; Faber Taylor, Kuo, \& Sullivan, 2002; Faber Taylor, Wiley, Kuo, \& Sullivan, 1998; Wells, 2000; Wells \& Evans, 2003). Natural landscape could offer spaces for activities or exercises, and as a result promote physical activity (Fjørtoft, Kristoffersen, \& Sageie, 2009; Tseng, Ding, Lee, \& Lu, 2013; Fjørtoft, 2001). The National Environmental Education Foundation in the United States recently began two important developments: 1) Improving the care for children's health and 2) Reconnect children with nature. The Children and Nature Initiative is joined with health care to encourage children to spend time outdoors and connect children and their family with parks or other natural environments. The final purpose of these benefits for children staying in the natural environment is to improve physical health, but the exploration of intermediary factors between environment and health is still absent.

Mayer, Buehlman-Senecal and Dolliver (2009) used the connectedness of nature as intermediate variable to explore positive affect and the ability to reflect on a life problem, and this could clarify the overall impact that natural landscape has on children. Due to the lack past studies in exploring the overall positive benefits by being in the natural environment on children, many measurement factors are unclear and obscure. Therefore, children's daily course is used in this study to explore the possible contact of different levels of natural landscape environment. Such connections include social and psychological dimensions.

\section{Literature review}

\subsection{Structure Measuring the amount of contact with the natural landscape}

Nature can be used to describe a variety of outdoor environment, and not a completely antagonistic relationship to the built environment. Clayton and Opotow (2003) proposed nature is subordinate to human influence, through what is to plant, what is to provide, what is to tolerable and what is to eliminate; it is both direct and also by excluding its habitat. According to the Parks and Green Space Seminar organized by the Construction and Planning Agency in Taiwan in 1994, the definition of green space refers to land or water that maintains a stable growth of vegetation, which in a broad definition indicates an open space that could provide functions including ecology, landscape, disaster prevention and recreation. Parks and green spaces are classified into three levels and 13 kinds of functions; the first level is natural green area, the second level is regional green area, and the third level is urban 
green space (Construction and Planning Agency, Ministry of the Interior, R.O.C., 1996). The methods of contacting with the natural landscape include objective and perceived. Evans, Wells, Chan and Saltzman (2000) created the Housing Scale Instrument to measure the amount of nature in a residential environment, which includes the quantity of naturalness of a window view, the number of indoor living plants and the material of the outdoor yard. Wells (2000) used long-term tracking method to examine the impact of natural greenery in the residential area on children's cognitive functions.

\subsection{Involvement of natural landscape}

When it comes to measuring the activities of a natural landscape, reliability and validity testing methods have not been developed yet, but activities in the natural environment is still a kind of leisure involvement. In terms of involvement measurement, scholars believed involvement should comprise behavioral and social psychological aspects (Gunter \& Gunter, 1980; Kim et al., 1997). For the behavior aspect, it should include the specific extents of time and frequency one spent in the natural environment, as well as the number of times one engaged in natural experiences. Kellert (2002) mentioned three kinds of ways to contact with the nature: Direct, indirect and vicarious /symbolic. Direct experience is the direct contact with the natural environment and non-human species, including playing in abandoned open spaces, neighborhood parks, forests, etc.; indirect experience includes physical contact and context with more restriction, curriculum and management; alternative/symbolic experience is the experience of any non-physical contact, such as through the media. Previous studies rarely discussed what kind of natural environment children have been in could form their natural experience.

- Viewing or being in nature

Past studies on children and the natural environment mostly used the green volume of the window view, or the natural variations in cross-sites as their focus (Faber Taylor et al., 2002; Coley et al., 1977). Studies have shown that the natural landscape environment would affect children's cognitive function, attention, play, and interaction with adults (Wells, 2000; Faber Taylor, Kuo, \& Sullivan; 2001; Coley et al., 1977; Faber Taylor et al., 1998).

- Horticulture and foraging activities

Horticultural activities are also sledom mentioned in the past. However, Pretty, Peacock, Sellens, \& Griffin (2005) have spoken of the contact with nature can be divided into three levels; first is viewing nature, followed by people being in nature and finally, actively participating and involving in nature: such as gardening, farming, hiking, camping, cross-country running, horseback riding or interacting with nature. Chipeniuk (1995) examined the impact of foraging during childhood and its impact to their future environmental knowledge. It was noted that those who had foraged more diversely during their childhood or adolescence, had better knowledge of biological diversity. Lohr and Pearson-Mims (2005) pointed out that childhood activities, such as picking fruits and vegetables, planting trees and taking care of plants, and spending time in parks or outdoor, can significantly predict their belief in their adulthood.

- Media \& Books

Some studies mention the nature experience from media and books would affect children's contact with nature and predict their future ecological center of life and anthropocentric belief (Sward, 1999; Ewert, Place, \& Sibthorp, 2005). This is also what Kellert (2002) mentioned as the vicarious/symbolic experience.

- Organizations and associations participation

Kellert (1985) indicated children who only learn about animals in zoos or at school lack appreciation (affective level), have less knowledge (cognitive level) and are less concerned about animals. The security in the natural environment experience, the social support when engaged in the experience, and indirect contact with nature, such as whether have joined natural-related associations, and whether attended unofficial outdoor environmental education programs, are all one of the significant reasons affecting them (Larson, Castleberry, \& Green, 2010).

- Effect of family members or relatives

Children's nature views are significantly affected by their parents. O'Brien (2009) noticed if people have not been to wilderness and green fields during childhood, they will not use these spaces when they grow up, and moreover, will be unable to develop a natural connection with the society, culture and emotion. Louv (2005) also mentioned that many parents forbid their children to explore the wild natural environment, because the parents 
themselves are not familiar with those natural environments and worry about the safety of children. Other role models and pleasant memories of natural recreation areas during childhood and adolescents will positively affect people's interest in the natural environment, and thereby protect the environment (Peterson, 1982; Tanner, 1980; Chawla, 1998, 2007; Chawla \& Cushing, 2007).

\subsection{Children's natural landscape experience and health}

Bowler, Buyung-Ali, Knight and Pullin (2010) divided health promotion methods into two ways: 1) Natural environment has intrinsic qualities; 2) The natural environment provides physical activities. Intrinsic quality is to explore the potential direct impact on the natural landscape environment, which is based on the "attention restoration theory" proposed by Kaplan and Kaplan (1989) and the "psychological theory of evolution" by Ulrich (1983). Physical activity is an indirect method to promote health. The health effect on children caused by natural environment in literatures can be divided into physiological and psychological levels. Physiological health means health of the physical body, and health on the psychological level includes reducing stress, increasing attention, providing positive emotions and improving self-esteem.

- Physical health

Natural environment provides a space for activities or movement, and thereby increases physical activity (Kacynski \& Henderson, 2007; Pretty, Peacock, Hine, Sellens, South, \& Griffin, 2007). Burdette, Whitaker and Daniel (2004) interviewed parents with kids in kindergarten and found comparing to indoor activities, physical activities usually happen in outdoor play time. If children in the age of 10-12 years stay outdoors for more than an hour, they will have 27 minutes more of physical activity time per week, and the overweight rate will decrease from $41 \%$ to $27 \%$. The amount of greenery near home and the accessibility to the park also have an impact on physical activity. Bell, Wilson and Liu (2008) followed children ages 3-16 years old from low-income families, and found increasing amount of vegetation caused lower odds in BMI. Potwarka, Kaczynski and Flack (2008) found the weight of respondents in a park with play features is five times the difference compared with those respondents in a park without playgrounds in Canada. Dyment and Bell (2008) investigated and evaluated which green facilities on campus would affect students' physical activity; $70 \%$ of the respondents indicated that these facilities can increase the light- moderate physical activity, and $50 \%$ replied green space on campus promotes higher vigorous activity than those without them. Fjørtoft, Kristoffersen, and Sageie (2009) discovered that there are more boys playing football and other physical activities than girls on the asphalt pavement, and schools in the rural area provides opportunities to play in the woods and attracts more girls. Tseng, Ding, Lee, \& Lu (2013) also found that students playing on the sports field can get more moderate physical activity, followed by buildings and squares. Fjørtoft (2001) surveyed five to seven-year-old children in Telemak, Norway, and children who played games in the natural environment had higher physical scores than those who played in the traditional playground.

- Reduce stress and enhance positive emotion

Children's stress is also a point of concern. Research on natural environment and children's health have also talked about natural environment can relieve stress from children, provide positive emotion and raise selfesteem. Wells and Evans (2003) pointed out that children living in a more natural area have lower stress, and mentioned nearby nature provides social support in rural areas, and restores children's attention to help solve problems. White \& Stoecklin (1998) presented the benefits for children to play in the natural environment, and they interact intimately with nature through exploration, discovery and children's imagination.

- Increase attention span

Natural surroundings can also improve attention span, particularly for hyperactive children. Kaplan proposed the "attention restoration theory" which stated natural environment can restore mental fatigue after long-term focus, and can also help people who have difficulty concentrating, as well as those who are easily irritated and distracted. Faber Taylor, Kuo and Sullivan's (2001) investigation showed activities created in natural environment are easier to appoint as well as improve concentration. Moreover, by increasing the amount of tree coverage of a space can reduce attention deficit. Kuo and Faber Taylor (2004) found that natural environment and natural environment activities can significantly reduce the symptoms of hyperactivity, much better than doing the activities in an indoor environment. Faber Taylor and Kuo (2008) also found that children in the park group have 
more positive self-evaluated experience, and recommended that natural environment can be used to treat hyperactive children. McCurdy, Winterbottom, Mehta and Roberts (2010) discuss why natural environment can be helpful on children's attention deficit; it is because hyperactive children spend time in the natural environment, and watching various forms of nature can improve healing efficiency and enhance the feel of well-being. Kaplan (2001) proposed the natural environment may be the most effective content of cognitive behavioral therapy, but more related research are needed.

- Improve self-esteem

Contact with nature can improve the well-being of children and adolescents, and many studies have used selfesteem instead of psychological well-being. Wood, Angus, Pretty, Sandercock and Barton (2012) asked 25 teens to view natural and artificial scenery while exercising; exercise can have positive effects on mood and selfesteem, but the impact of different environments is not high. Barton and Pretty (2010) analyzed 10 British studies and found that after doing green exercise in natural environments, both men and women have a similar degree of improvement in self-esteem. Earthman (1986) and Lilley (1986) indicated comfortable visual environment would help students reduce brutality caused by stress. Korpela (1992) investigated 144 senior high school teenagers and asked them to write an essay about their favorite environment, and describe the situation and their emotion context and experience when they seek for their preferred environment. The considerations of these teenagers when selecting their preferred environment partly came from the effort to maintain self-esteem and personal self-expression, and the interpretation of these experiences can be regarded as an environmental self-regulation.

- Social behavior

Natural environments can not only promote social behavior but help children learn to get along with their peers and compliance with social norms. Moore and Wong (1997) also talked about how natural environment is critical for the healthy growth of children because natural environment will stimulate all their senses, and leisure play can be combined with proper learning. Louv (2005) also stated one of the reasons nature can relieve emotion, is perhaps green space can promote social activity and thus can obtain more social support. Children living in areas with easy access to do outdoor activities can make more friends (Hüttenmoser, 1995). The natural environment can also become a haven for teenagers when they are feeling down, and provide some relief for the feeling of loneliness (Korpela, 1992). Pellegrini and Bohn (2005) believed outdoor physical activities during recess can provide opportunities for students to interact with peers, and learn to adjust their thinking and accept the views of others, in order to continue to maintain and enjoy the pleasure of interacting with peers.

- Disease

- Vitamin $\mathrm{D}$ has been proven to be a benefit of contacting with nature. Children who lack of outdoor activities would not be able to obtain enough Vitamin D. Maas, Verheij, Vries, Spreeuwenberg, Schellevis and Groenewegen (2009) investigated 24 kinds of diseases and found seven types of them are related to the amount of natural environment. Especially when it comes to children, people with depression and anxiety disorders have a strong relationship with the residence's amount of nature, and whether it is children or groups with low socioeconomic background, the importance of natural environment in their neighborhood was also put forward. From the studies above, kids may gain many physical and mental health benefits by contacting with nature.

However, past studies focus on exploring only a particular part of interest, and are in lack of overall health (physical or mental) considerations. Therefore, this study proposes the following four hypotheses:

- H1 Behavioral level involvement in the natural environment has a positive impact on children's physical activity.

- H2 Behavioral level involvement in the natural environment has a positive effect on children's social and psychological connectedness of nature.

- H3 Behavioral level involvement in the natural environment has a positive impact on health.

- H4 Children's physical activity has a positive effect on physical and mental health.

- H5 Psychosocial aspect of connectedness of nature has a positive effect on children's physical and mental health. 


\section{Method}

\subsection{Research framework}

This study is a "fundamental type" of empirical quantitative research. Statistical analysis is used to verify the relationship between the variables, and attempts to establish a model for children's health benefit and their contact with the natural landscape environment. Therefore, this study proposes the contacting levels of natural environment will affect children's actual involvement degree in different landscape environments, and this landscape environment involvement degree will also affect the physical activity of children's physiological aspect and nature connectedness of their socio-psychological aspect, as well as children's health. Children's physical activity and connectedness of nature will have a positive impact on the final health outcomes. The framework of this study is shown in Figure 1.

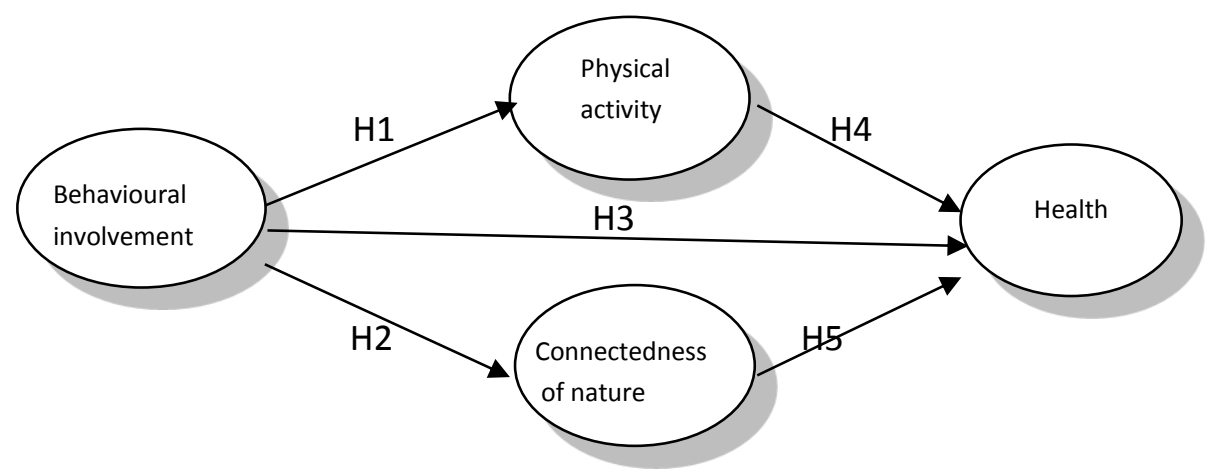

Fig. 1. Research framework

\subsection{Research tool}

- Contact with nature in behavior level

Previous studies have investigated the effects of the amount of natural landscape around children's home and neighborhood and the view of outside the window (Faber Taylor, Kuo, \& Sullivan, 2001), the degree of natural living environment (Evans, Wellsm Chan, Saltzman, 2000; Wells \& Evans, 2003; Faber Taylor, Kuo, \& Sullivan, 2001), naturalness of the neighborhood, and the degree of accessibility of the natural environment (Wells \& Evans, 2003). In this study, we ask the respondent to document their time spent on campus, green spaces near their homes (neighborhood parks) and rural areas or natural forest environments during the week.

- Children's connectedness of nature

In this study, natural environment experiences are considered as a kind of involvement, which includes behavioral and social-psychological aspect. Social psychology is a long-term, permanent effect that can be explored through connection of nature. Cheng and Monroe (2010) proposed The Connection to Nature Index $(\mathrm{CNI})$ which includes the four dimensions of physical, biological empathy, openness and a sense of responsibility, containing a total of 17 questions. This scale is about measuring trait status, and is consistent with this study's involvement in the social psychological aspect.

- Children's physical activity

The Physical Questionnaire for Older Children (PAQ-C) authorized by Professor Kowalski from Canada is used to measure children's physical activities. $P A Q-C$ is a self-administered, 7-day recall instrument. Moderate to vigorous physical activities throughout the elementary school year for students in grades 4 to 8 ( 8 to 14 years of age) are evaluated. Almost every question is scored on a five-point Likert scale, each dimension is added to 
calculate the average total score; the higher scores represent higher levels of physical activity, otherwise is lower.

- Children's health status

Health is divided into physical health, physical activity level and broader health coverage level of quality of life in this study. Children's health quality of life measurement tool can be divided into the general measurement tool and specific disease measurement tool. The advantage of general measurement is having a population reference value established from a larger sample pool, and can be used as a reference when comparing the quality of life score. Varni, Seid \& Rode (1999) proposed Pediatric Quality of Life Questionnaire (PedsQL) for the measurement of physiological function (8 questions), emotional function (5 questions), social function (5 questions) and school function (5 questions). A total of 23 questions suitable for children 5-18 years old should be answered by the respondents. This study obtained the fourth edition of the scale authorized by Varni, and uses a 5-point Likert scale to perform measurement (1 as never had a problem -5 as there is always a problem) (Gkoltsiou, Dimitrakaki, Tzavara, Papaevangelou, Varni \& Tountas, 2008).

\subsection{Research subjects and sampling locations}

One hundred students participated in the preliminary test of this study in March, 2014. Before carrying out the initial survey, consent forms were handed out to the parents by the teacher. Later between May and June of 2015, a large scale investigation went underway. Questionnaire surveys were conducted to fifth and sixth-grade students due to their better cognition. Stratified sampling was used based on the size of each elementary school, and one to two schools from each size category were randomly selected. A total sample of five elementary schools was selected, and we asked each school to recommend one class each from the fifth and sixth grade for the survey. Before answering the questions, a research consent form was handed out by the teacher to inform the students the purpose and operation process of this study, and this whole process took about 5 minutes. When the respondents agreed do the survey, the teacher will then distribute the questionnaires. This questionnaire takes about $30-40$ minutes to complete.

\section{Results}

\subsection{The sample analysis}

The study period was between May to June, 2014, and it was carried out in sampled elementary schools in Hsinchu City. Based on the number of classes and campus area of each school, elementary schools in Hsinchu City are categorized into four levels, following the principle of each student should have at least 12 square meters of the school area. One school from each category was randomly selected, and 5 elementary schools were sampled. A total of 241 effective questionnaires were collected, 53 subjects (22\%) were from small schools, 118 subjects (49\%) were from medium schools, and 70 subjects $(29 \%)$ were from large schools; $125(51.9 \%)$ were boys, and 116 (48.1\%) were girls. Of all the subjects, 105 (43.6\%) were fifth graders, and $136(56.4 \%)$ were sixth graders.

Family socioeconomic status calculated by the parent's education and occupational level can be divided into three levels of low, medium and high. Subjects were mostly in the "low socioeconomic status" and "medium socioeconomic status". Most subjects were within the normal range of body weight, and did not have many obesity problems. The average BMI was 18.3, indicating the majority of students were underweight. Most subjects have only one sibling (53.1\%); $64.3 \%$ of the subject felt their personality was lively and outgoing, $29.9 \%$ felt they were prim and proper, and the rest felt they were reserved and quite. As for the parental parenting style, authoritative parenting had the highest percentage, followed by permissive-indulgent parenting. Most subjects home owns a car (217 person, $90 \%)$, as well as a motorcycle $(11 \%)$ and a bicycle $(90 \%)$. 


\subsection{The scores of children's nature involvement, physical activity and health}

The average time of subject's contact with nature at the school level is 15.54 hours per week, the park level is 2.45 hours, and the natural forest level is 2.40 hours. The subject's highest physical activity score is 4.88 and the lowest is 1.16 , with an average score of 2.99 . Measurement of subject's health is divided into physical and psychological health, and was first converted to 0-100 using linear transformation. Total score of physical health equals total score of physiological health. Subject's average physical score is 82.40 , and average psychological score is 84.40 .

\subsection{The Connection to Nature Index}

For the measurement of connection to nature, question no.46 "People have no right to change the natural world" was removed due to its greater dispersion. After putting natural experience through exploratory factor analysis, the $\mathrm{KMO}$ value is 0.89 (KMO >0.5), spherical test chi-square value is $1611.16, \mathrm{p}$ value $=0.000(<0.05)$ reaching significant level. Principle component analysis was used and rotated using varimax method, and four categories were extracted respectively named "enjoyment of nature", "preference and empathy", "sense of belonging" and "responsibility". The explained variance is $60.609 \%$, which is in the acceptable range.

\subsection{Path Analysis of Hypothesis}

Path analysis was used to verify the hypothesis, which is mainly used to analyze the causal relationship between the variables. In this study, multiple regression analysis (stepwise method) was used to examine the path coefficient between the variables, with t-test (significant levels of 0.5 ) to examined whether the standardized regression coefficient is significant, and analyze the direct and indirect effects on various facets. Finally, significant variables will be selected and explained.

Stepwise regression analysis was used to test hypothesis 1 . The regression equation $F$ value of experience of natural landscape on behavioral aspect is 7.96 . In the regression analysis model, the parks and forest variables have reached significant level. This indicates the two variables of experience of natural landscape can effectively explain the physical activity variance of 0.063 . This result shows hypothesis 1 is established. To test hypothesis 2 , in the enjoyment of natural aspect, the regression equation $\mathrm{F}$ value of all three dimensions were not low. The behavioral aspect of experience in the forest can be predicted in "enjoyment of nature", "preference and empathy" and "a sense of belonging".

This study has separated health as physical health and psychological health. Only the experience of natural landscape in the forest can predict the psychological health significantly, but not the physical health. There is no significant influence of physical activity on psychological health; indicating physical activity is in lack of predictive power for psychological health. Physical activity can effectively predict physical health but not the mental health. Therefore, for hypothesis 5 the connectedness of nature for health, only the responsibility of connectedness of nature has predictive power influence on both dimensions of health.

\section{Conclusion and suggestions}

This study proposed a model of the different levels of natural experience for the children's physical activity and health, and results show contact of the natural landscape on school campus does not cause a high amount of physical activity, but the neighborhood park and forest can provide higher physical activity. The time children spent on school campus is no less than that in parks or woodlands. However, contact on school campus cannot increase the amount of physical activity, thus more contact with natural parks and forest should be promoted. Also, echoing previous studies' suggestions, children who spend time in the outdoors are more active and energetic (Davis, Rea, \& Waite, 2006; Dyment \& Bell, 2008; Bell, Wilson, \& Liu, 2008; Potwarka, Kaczynski, \& Flack, 2008). 


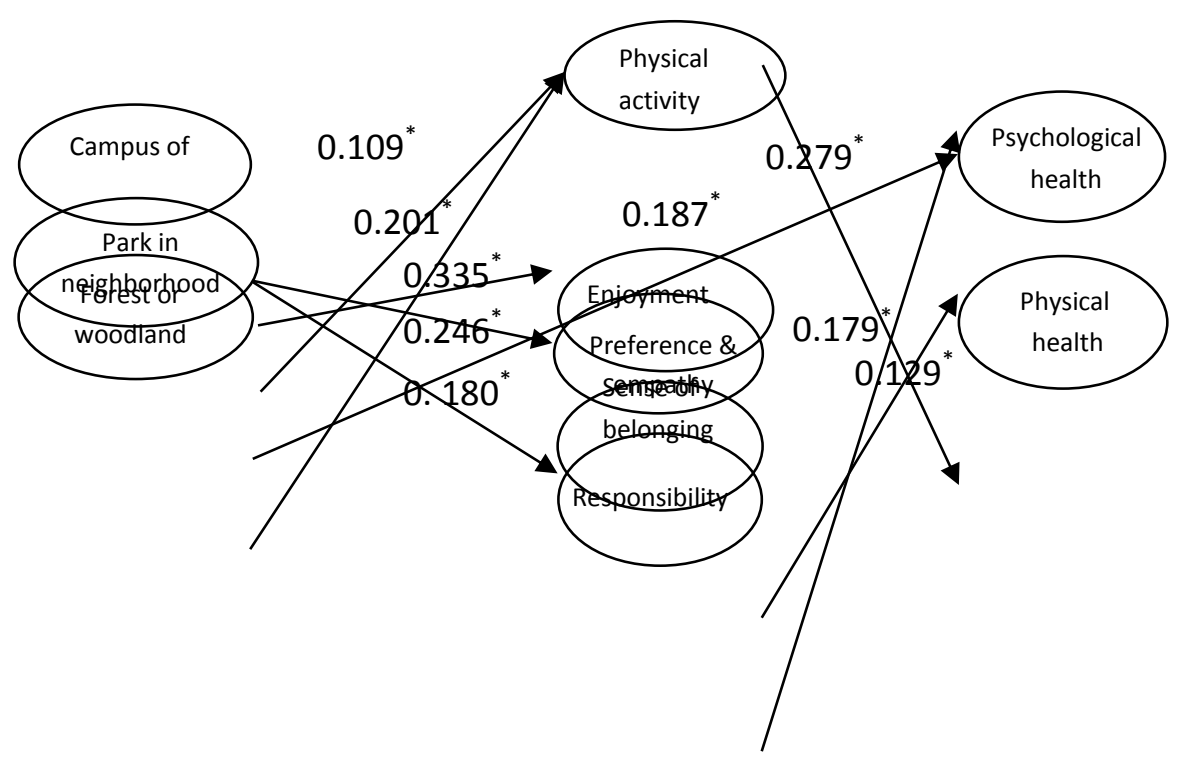

Fig. 2. Path analysis

For the connection of nature, only contact with nature at the forest has significant positive influence on "enjoyment of nature", "preference and empathy" and "a sense of belonging". Contact with nature at forest level have a positive impact on psychological health, and physical health is caused by the amount of physical activity. Although the behavioral level of natural experience cannot affect the "responsibility" of the connectedness of nature, responsibility can have a positive effect on the physical and psychological health of children. Wells and Evans (2003) pointed out that children living in more natural areas have less stress, it can also restore their attention as well as help solve problems. This study found only the experience of nature at the forest level have a significant positive creation with the connectedness of nature and psychological health, perhaps this is because the naturalness degree of home and neighborhood among Taiwan, Europe, and the United States are different. Other scholars suggested that nature can improve attention but most of them only compared urban and non-urban environment (Faber Taylor, Kuo, \& Sullivan, 2001; Faber Taylor \& Kuo, 2008; McCurdy, Winterbottom, Mehta, \& Roberts, 2010). This study found that in Asian countries, if people want children to get the positive effects of natural experience, it will be more effective when placing them in the forest or more natural area.

This study first attempted to use behavior and social dimensions to explore the natural experience, and only uses the actual extent of involvement in nature to link to the psychosocial dimension, and extends to physical activity and health of children. Many children's physical activities and health-related variables which are influential were not discussed in depth. We recommend follow-up studies to add in environmental factors, personal factors of children, and activity factors, etc. As for the research tools, the majority of research tools in this study are questionnaires, and when measuring physical activity, many are done through equipment; therefore, it is recommended they could be used in subsequent studies.

In this study, the positive impact of the forest is surprisingly higher than the natural behavior of other levels. We recommend when promoting environmental education, it can be held in outdoor natural spaces in rural areas. When visiting these places, they are often accompanied by a lot of outdoor recreation activities such as fishing, hiking, and camping, etc.; these activities have a positive benefit for children and can be a good reference for parents, teachers and recreation park management units. 


\section{References}

Bartleet, S. N. (1997). No place to play: Implications for the interaction of parents and children. Journal of Children and Poverty, 3, 37-48.

Barton, J. \& Pretty, J. (2010). What is the best dose of nature and green exercise for improving mental health? Amulti-study analysis. Environmental Science and Technology, 44, 3947-3955.

Bell, J. F., Wilson, J. S., \& Liu, G. C. (2008). Neighborhood greenness and 2-year changes in body mass index of children and youth. American Journal of Preventive Medicine, 35(6), 547-553.

Bowler, D. E., Buyung-Ali, L. M., Knight, T. M., \& Pullin, A. S. (2010). A systematic review of evidence for the added benefits to health of exposure to natural environments. BMC Public Health, 10, 456.

Burdette, H. L., Whitaker R. C., \& Daniel, S. R. (2004). Parental report of outdoor playtime as a measure of physical activity in preschool-aged children. Arch Pediatric Adolescent, 158, 353-357.

Chawla, (2007). Childhood experience associated with care for the natural world: A theoretical framework for empirical results. Children, Youth and Environments, 17, 144-170

Chawla, L. \& Cushing, D. (2007). Education for strategic environment behavior. Environment Education Research, 13, 437-452.

Chawla, L. (1998). Significant life experience revised: A review of research on sources of environmental sensitivity. The Journal of Environmental Education, 29(3), 11-21.

Cheng, J. C. H., \& Monroe, M. C. (2012). Connection to Nature : Children's Affective Attitude Toward Nature. Environment and Behavior, 44(1), 31-49.

Chipeniuk, R. (1995). Childhood foraging as a means of acquiring competent human cognition about biodiversity. Environment and Behavior, 27(4), 490-512.

Clayton, S., \& Opotow, S. (2003, Eds.). Identity and the natural environment. Cambridge, MA: MIT Press.

Coley, R. L., Kuo, F. E., \& Sullivan, W. C. (1997). Where does community grow? The social context created by nature in urban public housing. Environment \& Behavior, 29, 468-494.

Davis, B., Rea, T., \& Waite, S. (2006). The special nature of outdoors: Its contribution to the education of children at aged 3-11. Australian Journal of Outdoor Education, 10(2), 3-12.

Dyment, J. E., Bell, A. C. (2008). Grounds for movement: Green school grounds as sites for promoting physical activity. Health Education Research, 23, 952-962.

Earthman, G. I. (1986). Research needs in the field of education facilities planning. Paper presented at the Edusystems 2000 Intenational Congress on Education facilities, Values \& Contents (ERIC Document Reproduction Service No. ED 283301), Jerusalem, Isreal.

Evans, G. W., Wells, N. M., Chan, E., \& Saltzman, H. (2000). Housing quality and mental health. Journal of Consulting and Clinical Psychology, $68,526-530$.

Ewert, A., Place, G., \& Sibthorp, J. (2005). Early-life outdoor experiences and an individual's environmental attitudes. Leisure Sciences, 27, 225239.

Faber Taylor, A., \& Kuo, F. E. (2009). Children with attention deficits concentrate better after walk in the park. Journal of Attention Disorders, 12(5), 402-409.

Faber Taylor, A., Kuo, F. E., \& Sullivan, W. C. (2001). Coping with ADD: The surprising connection to green play settings. Environment \& Behavior, 33(1), 54-77.

Faber Taylor, A., Wiley, A., Kuo, F. E., \& Sullivan, W. C. (1998). Growing up in the inner city: Green space as places to grow. Environment \& Behavior, 30, 3-27. 
Faber Tylor, A., Kuo, F. E., \& Sullivan, W. C. (2002). Views of nature and self-discipline: Evidence from inner city children. Journal of Environmental Psychology, 22, 49-63.

Fjørtoft, I. (2001). The natural environment as a playground for children: The impact of outdoor play activities in pre-primary school children. Early Childhood Education Journal, 29(2), 111-117

Fjørtoft, I., Kristoffersen, B., \& Sageie, J. (2009). Children in schoolyards: Tacking movement patterns and physical activity in schoolyards using global positioning system and heart rate monitoring. Landscape and Urban Planning, 93, 210-217.

Gibson, J. (1979). The ecological approach to visual perception. Boston: Houghton Mifflin.

Gkoltsiou, K., Dimitrakaki, C., Tzavara, C., Papaevangelou, V., Varni, J.W., \& Tountas, Y. (2008). Measuring health-related quality of life in Greek children: Psychometric properties of the Greek version of the Pediatric Quality of Life Inventory ${ }^{\mathrm{TM}} 4.0$ Generic Core Scales. Quality of Life Research, 17, 299-305.

Gunter, B., \& Gunter, N. (1980). Leisure styles: A conceptual framework for modern leisure. Sociological Quarterly, 2, 361-374.

Hüttenmoser, M. (1995). Children and their living surroundings: Empirical investigations into the significance of living surroundings for the everyday life and development of children. Children's Environments, 12, 403-413.

Kaczynski, A. T., \& Henderson, K. A. (2007). Environmental correlates of physical activity: A review of evidence about parks and recreation. Leisure Sciences, 29, 315-354.

Kahn, P. H., \& Kellert, S. R. (2002). Children and nature: Psychological, Sociocultural, and Evolutionary Investigations. Cambridge, MA: MIT Press.

Kaplan, R. (2001). The nature of the view from home: Psychological benefits. Environment and Behavior, 33, 507-542.

Kaplan, R., \& Kaplan, S. (1989). The experience of nature: A psychological perspective. New York: Cambridge University Press.

Kellert, S. R. (1985). Attitude toward animals: Age-related development among children. Journal of Environmental Education, 16(3), 29-39.

Kellert, S. R. (2002). Experiencing nature. In Kahn, P., \& Kellert, S. (Eds.). Children and Nature. Cambridge, MA: MIT Press.

Kim, S. S., Scott, D., \& Crompton, J. L. (1997). An exploration of the relationships among social psychological involvement, behavior involvement, commitment, and future intentions in the context of birdwatching. Journal of Leisure Research, 29, 320-341.

Korpela, K. M. (1992). Adolescents' favourite places and environmental self-regulation. Journal of Environmental Psychology, 12(3), $249-258$.

Korpela, K., Kyttä, M., \& Hartig, T. (2002). Restorative experience, self-regulation and children's place preferences. Journal of Environmental Psychology, 22, 387-398.

Kuo, F. E., \& Faber Taylor, A. (2004). A potential natural treatment for attention-deficit/hyperactivity disorder: evidence from a national study. American Journal of Public Health, 94, 1580-1586.

Larson, L. R., Castleberry, S. B., \& Green, G. T. (2010). Effects of an environmental education program on the environmental orientations of children from different gender, age, and ethnic groups. Journal of Park and Recreation Administration, 28(3), 95-113.

Lilley, H. E. (1986). Student control as a planning and design factor in education facilities. Paper presented at the Edusystems 2000 International Congress on Education Facilities, Values \& Contents. (ERIC Document Reproduction Service No. ED 282338), Jerusalem, Israel.

Lohr, V. I., \& Pearson-Mims, C. H. (2005). Children's active and passive interactions with plants influence their attitude and actions toward trees and gardening as adults. Hort Techology, 15(3), 472-476.

Louv, R. (2005). Last child in the woods. Chapel Hill, NC: Algonquin Press.

Maas, J. M., Verheij, R. A., Vries, S. D., Spreeuwenberg, P., Schellevis, F. G., \& Groenewegen, P. P. (2009). Morbidity is related to a green living environment. Journal of Epidemiology Community Health, 63, 967-973.

Mayer, F. S., Frantz, C. M., Bruehlman-Senecal, E., \& Dolliver, K. (2009). Why is nature beneficial? The role of connectedness to nature. Environment and Behavior, 41(5), 607-643. 
McCurdy, L. E., Winterbottom, K. E., Mehta, S. S., \& Roberts, J. R. (2010). Using nature and outdoor activity to improve children's health. Current Problem Pediatric Adolescent Health Care, 5, 102-117.

Moore R., \& Wong, H. H. (1997). Natural Learning: The Life History of an Environmental Schoolyard. Berkeley, CA: MIG Communications.

Moore, R. C. (1986). Children's domain. London, England: Croom Helm.

O'Brien, L. (2009). Learning Outdoors: the Forest School Approach. Education 3-13, 37(1), 3-13.

Pellegrini, A. D., \& Bohn, C. M. (2005). The role of recess in children's cognative performance and school adjustment, Educational Researcher, 34(1), 13-19.

Peterson, N. (1982). Developmental variables affecting environmental sensitivity in professional environmental educators(Unpublished Master's thesis). Southern Illinois University, Carbondale, IL.

Potwarka, L. R., Kaczynski, A. T., \& Flack, A. L. (2008). Place to stay: Association of park space and facilities with healthy weight status among children. Journal of Community Health, 33(5), 344-350.

Pretty, J., Peacock, J., Hine, R., Sellens, M., South, N., \& Griffin, M. (2007). Green Exercise in the UK Countryside: Effects on Health and Psychological Well-Being, and Implications for Policy and Planning. Journal of Environmental Planning and Management. 50(2), 211-231

Pretty, J., Peacock, J., Sellens, M., \& Griffin, M. (2005). The mental and physical health putcomes of green exercise. International Journal of Environmental Health Resaerch, 15(5), 319-337.

Sebba, R. (1991). The landscape of childhood: The reflections of childhood's environment in adult memories and in children's attitudes. Environment \& Behavior, 23, 395-422.

Sobel, D. (1993). Children's special places: Exploring the role of forts, dens, and bush houses in middle childhood. Tucson, AZ: Zephyr Press.

Sward, L. L. (1999). Significant life experience affecting the environmental sensitivity of El Salvadoran Environmental Professionals. Environmental Education Research, 5(2), 201-206.

Tanner, T. (1980). Significant life experiences: A new research area in environmental education. The Journal of Environmental Education, 11(4), 20-24.

Tseng, T. A., Ding, T. J., Lee, A. J. Y., \& Lu, M. H. (2012). The relationship of the children's movement patterns and physical activity in school campus. Journal of Health Promotion and Health Education, 38, 27-48.

Ulrich, R. S. (1983). Aesthetic and affective response to natural environment. In Altman, I., \& Wohlwill, J. (Eds.), Human Behavior and Environment, Vol. 6: Behavior and Natural Environment (pp.85-125). New York: Plenum.

Varni, J. W., Seid, M., \& Rode, C. A. (1999). The PedsQL ${ }^{\mathrm{TM}}$ : Measurement model for the Pediatric Quality of Life Inventory ${ }^{\mathrm{TM}}$. Medical Care, 37 , 126-139.

Well, N. M., \& Lekies, K. S. (2006). Nature and the life course: Pathway from childhood nature experiences to adult environmentalism. Children, Youth and Environments, 16(1), 1-24.

Wells, N. (2000). At home with nature: Effects of "Greenness" on children's cognitive functioning. Environment and Behavior, 32, 775-795.

Wells, N., \& Evans, G. (2003). Nearby nature: A buffer of life stress among rural children. Environment and Behavior, 35, 311-330.

White, R., \& Stoecklin. V. (1998). Children's Outdoor Play \& Learning Environments: Returning to Nature. Accessed June 11, 2004 from www.whitehutchinson.com/children/articles/outdoor.shtml

Wood, C., Angus, C., Pretty, J., Sandercock, G., \& Barton, J. (2013). A randomised control trial of physical activity in a perceived environment on self-esteem and mood in UK adolescents. International Journal of Environmental Health Research, 23(4), 311-320. 